\title{
THE INFLUENCE OF INTERRUPTING THE BRAZING PROCESS OF HASTELLOY $X$ SUPERALLOY ON THE PROPERTIES OF THE JOINT
}

\begin{abstract}
In this paper, disruption of brazing process impact on behavior of filler metal and properties of the joint was investigated. Hastelloy $\mathrm{X}$ sheet samples were brazed using $\mathrm{Ni}-13 \mathrm{Cr}-4 \mathrm{Fe}-4 \mathrm{Si}-2,7 \mathrm{~B}$ filler alloy. Two identical sets of samples were heated in high vacuum, once load reached specified temperature process was interrupted. Subsequently, one set of samples was tested and second set was subjected to rebrazing in proper time and temperature, dedicated for used filler material. Disruption of the process in following temperature was analyzed: $930,960,1050,1127,1145,1170^{\circ} \mathrm{C}$. After both processes macroscopic observations of joint, peel test, static tensile test and spreadability analysis were carried out.
\end{abstract}

Keywords: vacuum brazing, Hastelloy X, nickel superalloy.

\section{Introduction}

Hastelloy $\mathrm{X}$ is one of the nickel-based superalloys, which is widely used in aviation industry due to its unique properties combinations [1]. Remarkable oxidation resistance combined with good strength characteristic up to $1200^{\circ} \mathrm{C}$, makes it a perfect material for parts in so-called hot section of the turbine engine, such as combustion chambers, afterburners or honeycomb sealings [2-4]. In modern jet engines these parts are complex assemblies, consisting of elements made from materials of different cross-section and form. Therefore, joining method is crucial in production process. Furnace brazing using nickel based brazing filler metals (BFM), with boron and silicon additions as melting point depressants, is known to be a proper method of joining assemblies made of heat-resistant nickel alloys, such as Hastelloy X [5]. This group of alloys offers good set of technological and physical properties and allows to receive high-strength joints, with good resistance for both corrosion and oxidation [6]. Ni-13Cr-4Fe-4Si-2,7B is a low carbon, nickel based braze alloy, with composition and properties similar to AWS BNi-1a and

\footnotetext{
${ }^{1}$ Kamil Krystek (corresponding author); Faculty of Mechanical Engineering and Aeronautics, Rzeszow University of Technology, al. Powstańców Warszawy 12, 35-959 Rzeszów, Poland, Pratt \& Whitney Rzeszow, Rzeszow, Poland.
} 
application range typical for nickel based filler metals. It can be found under trade name Amdry 915 [7]. It is also capable of filling very wide gaps [6, 7], which is especially important in brazing of sheet parts, where achieving satisfying fit is often difficult. Although brazing with nickel-based BFM appears to be well described process, due to its popularity in industry, many aspects of it are still being investigated. Ghasemi and Pouranvari investigated microstructure evolution [8] and intermetallic phase formation [9] of Hastelloy $\mathrm{X}$ brazed with $\mathrm{Ni}-4,5 \mathrm{Si}-3,2 \mathrm{~B}$ and $\mathrm{Ni}-13 \mathrm{Cr}-4.5 \mathrm{Si}-4.2 \mathrm{Fe}-2.8 \mathrm{~B}$ BFM, respectively. Many researchers focuses on effect of brazing on microstructure and properties of thin-walled honeycomb sealings made of Hastelloy X with nickel based filler metals [10]. In industry practice there are variety factors that might interrupt brazing process, i.e. power supply break, furnace malfunction or operator mistake. Results of such an event is a nonconforming joint, with partially melted filler alloy and incomplete filling of the gap. Risk of these aspects has to be taken into consideration in process planning, as they can occur on every stage of process and affect quality of final product.

As the sources in literature considering this problem are limited, the aim of this paper is to evaluate influence of interruption in brazing process on filler metal and joint properties. Tests were carried out on Hastelloy X nickel superalloy using Ni-13Cr-4Fe-4Si-2,7B brazing filler metal. During the tests, process was stopped at the different stages and subsequently repeated at the temperature dedicated for used braze alloy. After both processes, macroscopic observations of joints, static tensile tests, peel test and spreadability tests were carried out.

\section{Methodology}

\subsection{Experiment}

In present studies Hastelloy $\mathrm{X}$ nickel superalloy was brazed using Ni-13Cr-4Fe-4Si-2,7B filler metal. Chemical composition of used materials is shown in Table 1. In case to simulate interruption in brazing process, two sets of identical samples were heated in high vacuum with a rate of $10^{\circ} \mathrm{C} / \mathrm{min}$ to the temperatures from range of below solidus to above liquidus: 930, 960, 1050, 1127, $1145,1170^{\circ} \mathrm{C}$ and then cooled below $100^{\circ} \mathrm{C}$. Subsequently, first set of samples has been examined and the second set was rebrazed using the same atmosphere and heating rate, this time in temperature and time dedicated for analyzed BFM $1145^{\circ} \mathrm{C}$ for 10 minutes.

Following set of samples were used: 3 for static tensile test, 1 for peel test and 3 for spreadability test. Shape and dimensions of samples are shown on Fig. 1.

Samples were cleaned in ultrasound washer and assembled in configurations given on Fig. 1 using ball-tack welding positioning method. Lap length was $8 \mathrm{~mm}$. Gap was set to $0,05 \mathrm{~mm}$ using crevice tool. After positioning, joint area was additionally degreased with ethylic alcohol and blown with compressed air. Filler metal was applied in form of paste at the one side of the joint. To ensure repeatability, 
for spreading examination (Fig. 1c) BFM in form of $\varnothing 6 \times 0,05 \mathrm{~mm}$ foil was used, therefore initial nominal surface area of applied brazing filler alloy in this test was $28,27 \mathrm{~mm}^{2}$. Three circular pieces of foil were stacked on the sample, previously washed and degreased with ethylic alcohol and resistance welded to the surface.

Table 1. Chemical composition of investigated alloys $[1,7]$

\begin{tabular}{|c|c|c|c|c|c|c|c|c|c|c|}
\hline \multirow{2}{*}{ Alloy } & \multicolumn{10}{|c|}{ Chemical composition [\% wt] } \\
\hline & $\mathrm{Ni}$ & $\mathrm{Cr}$ & $\mathrm{Fe}$ & Mo & $\mathrm{Co}$ & $\mathrm{W}$ & $\mathrm{C}$ & $\mathrm{Mn}$ & $\mathrm{Si}$ & B \\
\hline $\begin{array}{c}\text { Hastel- } \\
\text { loy X }\end{array}$ & bal. & $\begin{array}{c}20,5- \\
23\end{array}$ & $\begin{array}{l}17- \\
20\end{array}$ & $8-10$ & $\begin{array}{l}0,5- \\
2,5\end{array}$ & $0,2-1$ & $\begin{array}{l}0,05- \\
0,15\end{array}$ & $\max .1$ & $\max .1$ & $\begin{array}{l}\max . \\
0,008\end{array}$ \\
\hline $\begin{array}{l}\text { Filler } \\
\text { metal }\end{array}$ & bal. & $12-14$ & $4-5$ & - & - & - & $\begin{array}{l}\max . \\
0,06\end{array}$ & - & $4-5$ & $2,5-2,9$ \\
\hline
\end{tabular}

a)

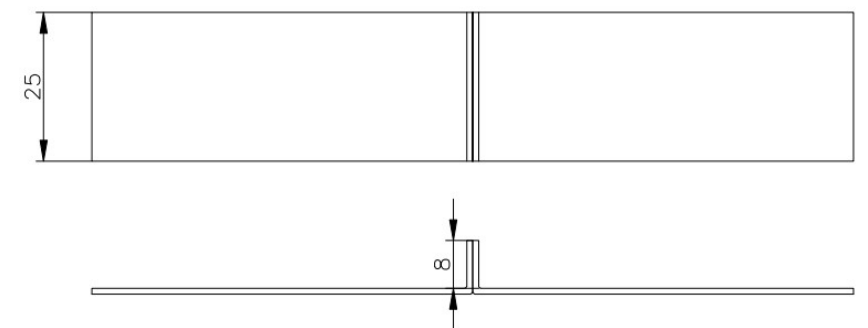

b)
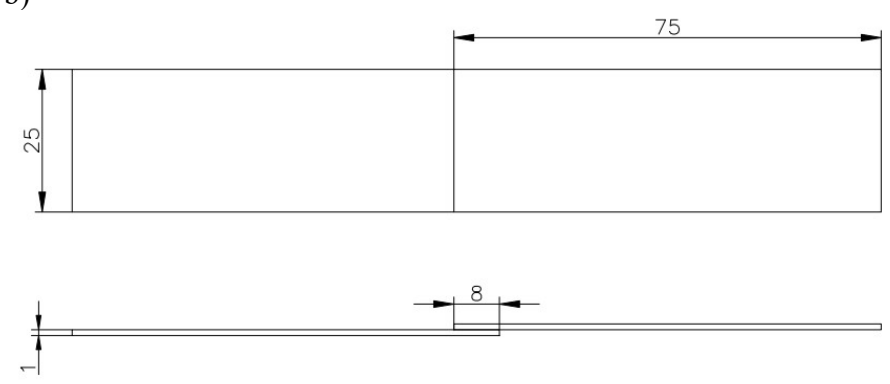

c)

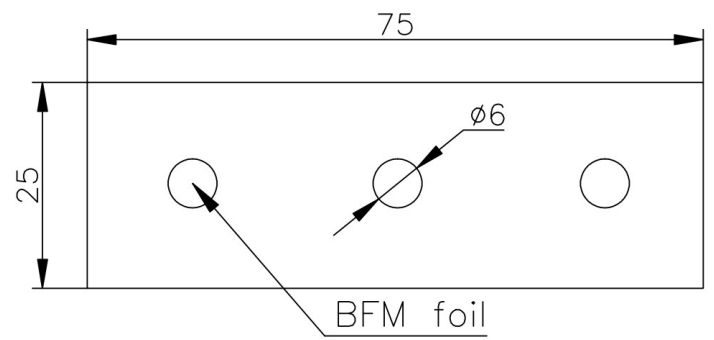

Fig. 1. Samples used for (a) static tensile tests, (b) peel test, (c) spreadabilty test. All dimensions given in milimeters 
Brazing processes (Fig. 2) were carried out in Seco/Warwick VP-4050/72HV vacuum furnace in Pratt \& Whitney Rzeszow.

a)

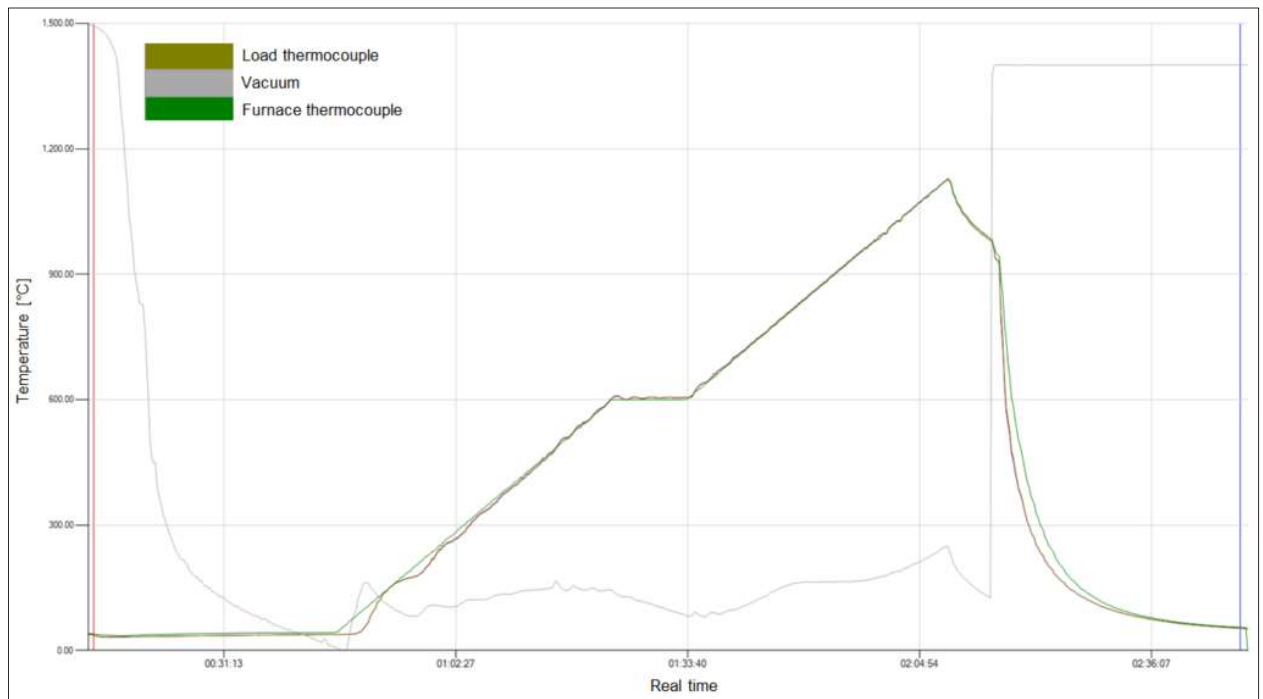

b)

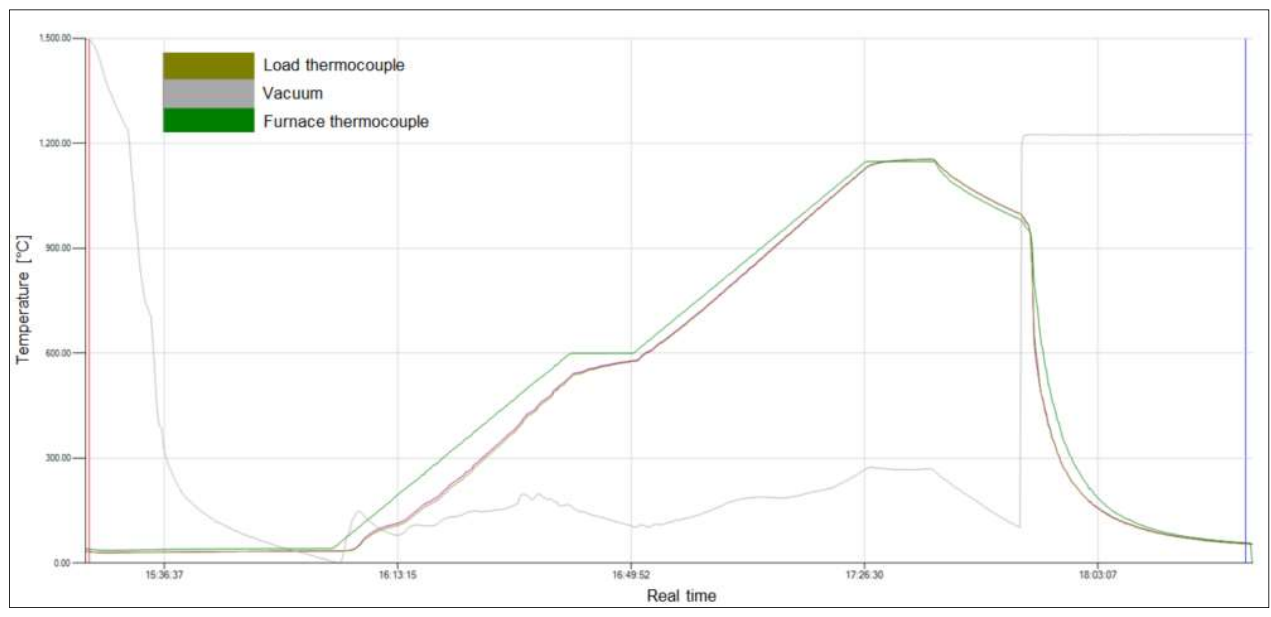

Fig. 2. Furnace graphs for process interrupted in $1127^{\circ} \mathrm{C}$ (a) and subsequent rebrazing (b). Rebrazing process was identical for each set of samples

Macroscopic observations were carried out using OPTA-Tech X2000 stereo microscope. Static tensile test was performed in Rzeszow University of Technology on Instron 3382 universal testing machine. 


\section{Results}

\subsection{Spreadability}

Wettability and spreadability, along with capillary force, are core terms in brazing technology. Both can be used to describe BFM ability to flow over surface of brazed elements, which is essential in successful formation of the joint. In this paper, area of droplets after both furnace processes was measured on macroscopic photography in two planes, as a distance between two parallel lines tangent to the edge of the halo created by the molten filler alloy (Fig. 3).

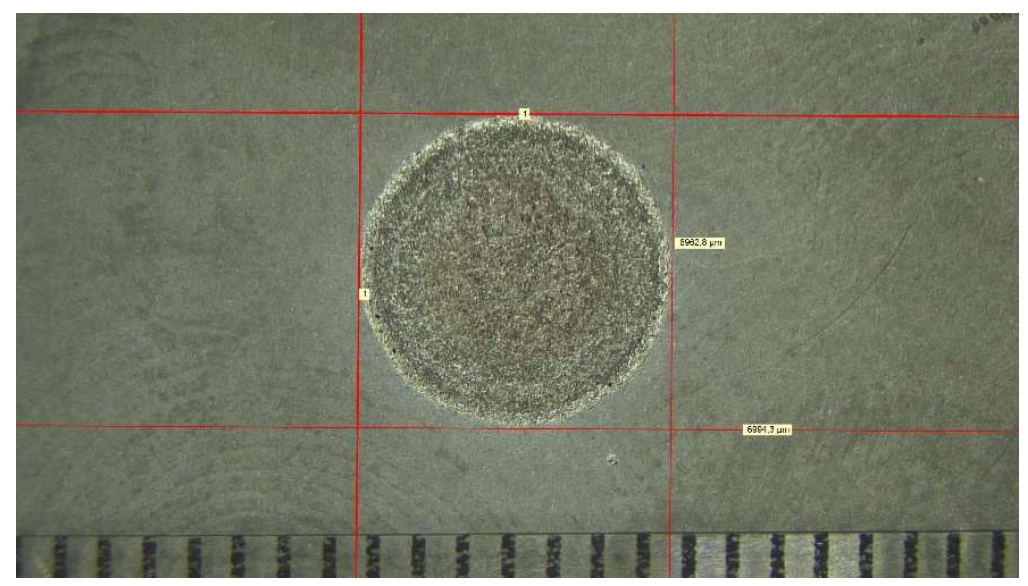

Fig 3. Measurement method of diameter in spreadability tests, process interrupted in $1170^{\circ} \mathrm{C}$

Table 2. Spreadability results. Samples after rebrazing marked with "R"

\begin{tabular}{cccccc}
\hline Sample & $\begin{array}{c}\text { 1st droplet avg. } \\
{[\mu \mathrm{m}]}\end{array}$ & $\begin{array}{c}\text { 2nd droplet } \\
\text { avg. }[\mu \mathrm{m}]\end{array}$ & $\begin{array}{c}\text { 3rd droplet } \\
\text { avg. }[\mu \mathrm{m}]\end{array}$ & Avg. of 3 $[\mu \mathrm{m}]$ & $\begin{array}{c}\text { Surface area } \\
{\left[\mathrm{mm}^{2}\right]}\end{array}$ \\
\hline 930 & 6081,2 & 6062,1 & 6063,55 & 6068,95 & 28,93 \\
\hline $930 / \mathrm{R}$ & 6758,5 & 6892,7 & 6742,85 & 6798,017 & 36,30 \\
\hline 960 & 6036,5 & 6017,6 & 6056,75 & 6036,95 & 28,62 \\
\hline $960 / \mathrm{R}$ & 6874,4 & 6566,6 & 7245,75 & 6895,583 & 37,34 \\
\hline 1000 & 6113,2 & 6070,8 & 5973,1 & 6052,367 & 28,77 \\
\hline $1000 / \mathrm{R}$ & 6497,8 & 6442,1 & 6534 & 6491,3 & 33,09 \\
\hline 1050 & 5293,2 & 6034,1 & 6050,25 & 5792,517 & 26,35 \\
\hline $1050 / \mathrm{R}$ & 6988,3 & 6954,4 & 6810,15 & 6917,617 & 37,58 \\
\hline 1127 & 6562,95 & 6959,05 & 6690,25 & 6737,417 & 35,65 \\
\hline $1127 / \mathrm{R}$ & 7148,45 & 6908,75 & 7445 & 7167,4 & 40,35 \\
\hline 1145 & 6686,6 & 6621,1 & 6863,25 & 6723,65 & 35,51 \\
\hline $1145 / \mathrm{R}$ & 7278,8 & 7498,35 & 7263,9 & 7347,017 & 42,39 \\
\hline 1170 & 6828,35 & 6915,3 & 6781,35 & 6841,667 & 36,76 \\
\hline $1170 / \mathrm{R}$ & 6972,95 & 7112,2 & 6978,55 & 7021,233 & 38,72 \\
\hline
\end{tabular}


In table 2 the spreadability results are presented. Due to high cooling rate and quick crystallization, diffusion of melting point depressants from filler alloy into base material was hindered, so remelting and additional spreading occurred during rebrazing. The results shows that surface area of droplets after rebrazing icreases as the temperature of the process interruption raises, which indicates that temperature of process disruption impacts on the spreadability of the filler metal, and in consequence might affect effects of the rebrazing. In highest analyzed temperature $\left(1170^{\circ} \mathrm{C}\right)$, which corresponds to overheating of the furnace load, lowest increase in the surface area of droplets was noted.

\subsection{Macroscopic observations of joints}

\subsubsection{Interrupted processes}

In lower range of tested temperature $\left(930^{\circ} \mathrm{C}, 960^{\circ} \mathrm{C}\right)$ no evidence of BFM melting nor capillary action were observed. Binder from brazing paste has evaporated due to high temperature, making it hard and brittle and revealing spherical powder particles (Fig. 4a). In $1050^{\circ} \mathrm{C}$ the filler metal has partially melted (Fig. 4b), however presence of the braze was not observed at the opposite side of the joint, which indicates that it was not filled. In $1127^{\circ} \mathrm{C}$ melting was not complete, but sufficiently advanced for capillary action to occur, which resulted in different appearance of braze alloy (Fig. 4c) and filling the joint. Processes interrupted above BFM liquidus temperature formed properly looking joints, meeting all requirements of visual inspection (Fig. 4d).

a)

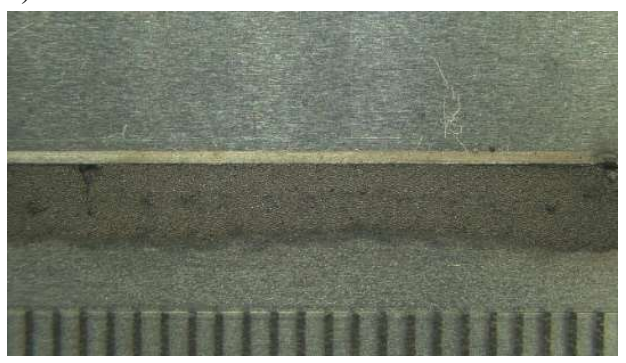

c)

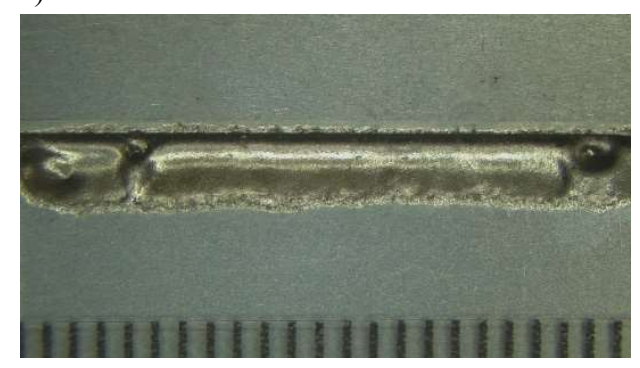

b)

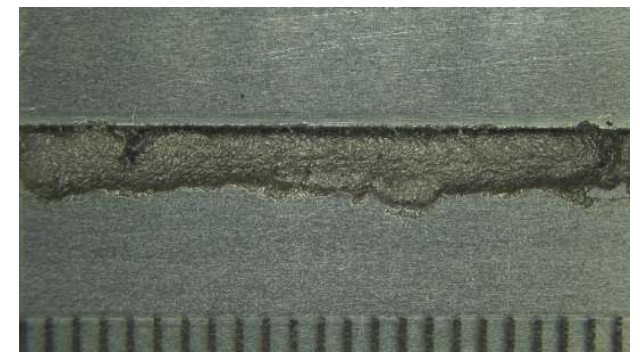

d)

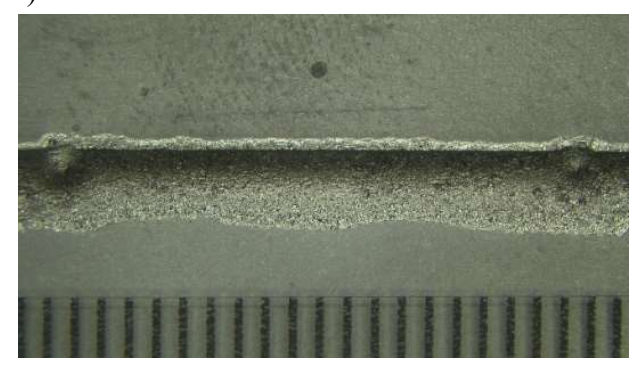

Fig. 4. Appearance of joints from process interrupted in: (a) $930^{\circ} \mathrm{C}$, (b) $1050^{\circ} \mathrm{C}$, (c) $1127^{\circ} \mathrm{C}$ and (d) $1145^{\circ} \mathrm{C}$. 


\subsubsection{Rebrazing}

All rebrazed samples shown visually conforming joint (Fig. 5), with proper meniscus on both sides. No significant differences between joint obtained in proper conditions and rebrazed joint from interrupted process were observed.

a)

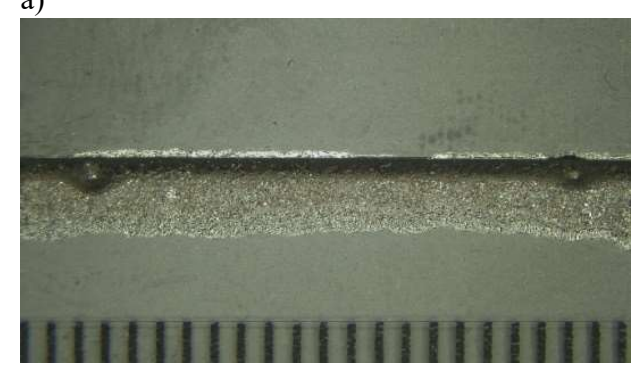

b)

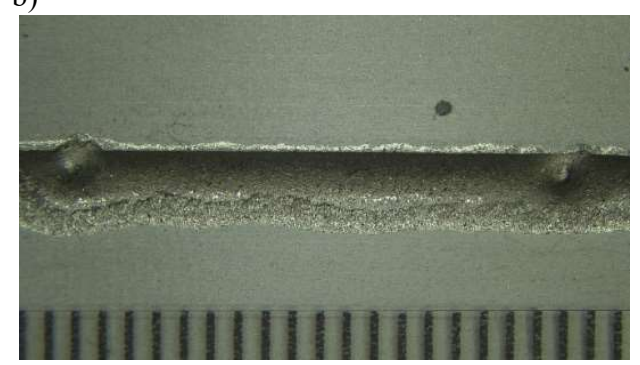

Fig. 5. Joints appearance after rebrazing in $1145^{\circ} \mathrm{C}$ for 10 minutes. Samples from process interrupted in: (a) $930^{\circ} \mathrm{C}$ and (b) $1127^{\circ} \mathrm{C}$.

\subsection{Peel test}

Peel test is the most commonly used destructive method in brazing joint quality inspection. Its aim is mechanical separation of brazed elements and subsequent assessment of coverage area, given in the percentage of the surface covered with braze filler material in relation to the total area subjected to brazing. Sample selection for peel test is crucial, as there are often problems with opening the lap joints. L-shaped samples used in this test facilitate the separation process, making the evaluation of the entire joint area possible. In this case, samples were separated using Zwick/Roell standard testing machine. Applied force was recorded during the test. Coverage and breaking load for samples from interrupted and from rebrazing processes are shown in Tables 3 and 4 respectively. Despite the use of dedicated samples, in three tests failure occurred through base material - in that case joints were subsequently opened using manual methods (results of these samples are bolded in Tables 3 and 4).

Table 3. Coverage and breaking load during peel test, samples from interrupted process. Results in bold correspond to failure through base material

\begin{tabular}{cccccccc}
\hline Sample & 930 & 960 & 1000 & 1050 & 1127 & 1145 & $\mathbf{1 1 7 0}$ \\
\hline Coverage [\%] & 0 & 0 & 0 & 40 & 100 & 98 & $\mathbf{1 0 0}$ \\
\hline Breaking load $[\mathrm{N}]$ & 315 & - & 210 & 8550 & 9920 & 10400 & $\mathbf{9 9 9 0}$ \\
\hline
\end{tabular}

Table 4. Coverage and breaking load during peel test, samples after rebrazing, Results in bold correspond to failure through base material. Parameters of all rebrazing processes were identical

\begin{tabular}{cccccccc}
\hline Sample & $930 / \mathrm{R}$ & $960 / \mathrm{R}$ & $1000 / \mathrm{R}$ & $\mathbf{1 0 5 0} / \mathbf{R}$ & $1127 / \mathrm{R}$ & $1145 / \mathrm{R}$ & $\mathbf{1 1 7 0} / \mathbf{R}$ \\
\hline Coverage [\%] & 100 & 100 & 100 & $\mathbf{1 0 0}$ & 100 & 100 & $\mathbf{1 0 0}$ \\
\hline Breaking load [N] & 8150 & 7890 & 9250 & $\mathbf{1 0 7 0 0}$ & 8200 & 8670 & $\mathbf{9 6 6 0}$ \\
\hline
\end{tabular}


In processes disrupted below and slightly above solidus no sign of filling the gap between mating elements was observed. Joints were not formed in these conditions, thus acquired breaking loads are low, adequate to the strength of ball-tack welds. Evidence of capillary action was found in $1050^{\circ} \mathrm{C}$, with approximately $40 \%$ of coverage area and significantly higher joint strength, confirming the presence of a bond. Higher range of tested temperature $\left(1127-1170^{\circ} \mathrm{C}\right)$ shown complete coverage of joint surface. $100 \%$ coverage was also observed on all joints after rebrazing.

Noticable differences in braking load, required to open joints, were observed. As shown in Table 4, lowest force was required when brazing was disrupted below solidus point. In case of $1127^{\circ} \mathrm{C}$ and $1145^{\circ} \mathrm{C}$, breaking load after rebrazing was lower than in original, deviated process. Although breaking load in terms of the peel test is a secondary parameter, it can be a highlight of a direction for a further research aimed for more detailed investigation and microstructure analysis.

\section{Conclusion}

Influence of the disruption of the brazing process on its certain stages on joint appearance and properties was presented. Different effects on joint appearance was observed, depending on the temperature of the process disturbance: from evaporating of the binder material from the filler metal only, through partial melting and incomplete filling of the joint, to complete melting and forming properly looking joint. Filler metal melted during rebrazing and after that process each joint met visual inspection requirements. Spreadability of the molten filler alloy found to be affected by process interruption. Surface area of filler material droplets after rebrazing was increasing with temperature of the original process disruption (Fig. 6).

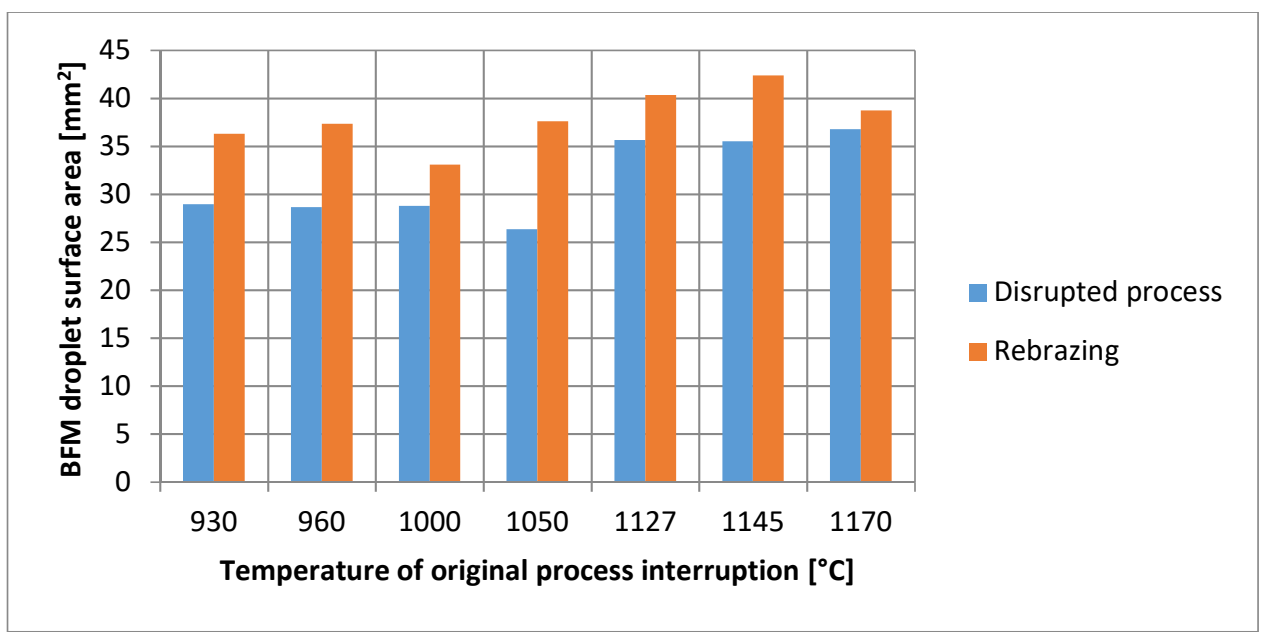

Fig. 6. Effect of brazing process interruption temperature on spreadability of filler alloy 
In highest tested temperature $\left(1170^{\circ} \mathrm{C}\right)$, which represents load overheating, lowest increase after rebrazing was noted. Peel test after interruption in $1050^{\circ} \mathrm{C}$ revealed $40 \%$ of joint area covarege. All processes stopped below that temperature shown no coverage, while all processes above $-100 \%$. Complete coverage was also observed on all samples after repeating the brazing process. Significant decrease in breaking load during peel test was noted in case of rebrazed samples from processes stopped in 1127 and $1145^{\circ} \mathrm{C}$. Peel test, as an experiment aimed for coverage assessment, can not be used to form credible conclusion about joint strength, nevertheless it may be used to set the direction for further investigation.

As mentioned in previous paragraphs, in case of lap joints proper selection of samples for particular test is important. Thickness of sheet metal samples used for static tensile tests in present studies $(1 \mathrm{~mm})$ was too thin compared to the lap length. In all tested samples, crack initiated in base material at the edge of the joint and propagated along the sample edge. That kind of results only allows to conclude that joint strength was higher than strength of the base materials, however it is not suitable for analysis of potential differences resulting from the process deviation.

Further test, with samples geometry dedicated for shear strength, as well as microstructure changes examinations, are planned.

\section{References}

[1] Haynes International, http://haynesintl.com/docs/default-source/pdfs/new-alloy-brochures/high-temperature-alloys/brochures/x-brochure.pdf?sfvrsn $=15 \mathrm{~b} 829 \mathrm{~d} 4 \_38$, Access date: 02.12.2019.

[2] Dul I.: Application and processing of nickel alloys in the aviation industry, Welding International, 27:1, 48-56.

[3] Romero-Jabalquinto, et al.: Feasibility of manufacturing combustion chambers for aeronautical use in Mexico. Journal of Applied Research and Technology 14 (2016), 167-172.

[4] Sporer D., Fortuna D.: Selecting materials for brazing a honeycomb in turbine engines. Welding Journal 2014, Vol. 93(2), 44-48,

[5] American Welding Society (AWS) C3 Committee on Brazing and Soldering. Brazing Handbook, 5th ed. American Welding Society: 550 N. W. LeJeune Road, Miami, FL33126, United States of America, 2007; pp. 164.

[6] Elrefaey A.: High-temperature brazing in aerospace engineering. Woodhead Publishing Series in Welding and Other Joining Technologies 2012, Pages 345-383.

[7] https://www.oerlikon.com/ecomaXL/files/metco/oerlikon_DSM-0285.1_Amdry_915_ Series.pdf, Access date: 02.12.2019.

[8] Ghasemi A., Pouranvari M.: Microstructural evolution mechanism during brazing of Hastelloy X superalloy using Ni-Si-B filler metal. Science and Technology of Welding and Joining 23 (2018), 441-448. 
[9] Ghasemi A., Pouranvari M.: Intermetallic phase formation during brazing of a nickel alloy using a $\mathrm{Ni}-\mathrm{Cr}-\mathrm{Si}-\mathrm{Fe}-\mathrm{B}$ quinary filler alloy. Science and Technology of Welding and Joining 24 (2019), 342-351.

[10] Ulan kyzy, S., Völkl R., Munz O., Fischer T., Glatzel U.: The Effect of Brazing on Microstructure of Honeycomb Liner Material Hastelloy X. Journal of Materials Engineering and Performance 28 (2019), 1909-1913.

http://dx.doi.org/10.7862/rm.2021.03 